\title{
Novel open cell aluminum foams and their use as reactive support for zeolite crystallization
}

\author{
S. Barg • C. Soltmann · A. Schwab - D. Koch • \\ W. Schwieger · G. Grathwohl
}

\begin{abstract}
Open cell aluminum (Al) foams are developed in this work by a novel direct foaming process in which a low concentrated alkane phase is emulsified in a stabilized $\mathrm{Al}$ powder suspension. In this versatile technique, the porosity parameters are adjusted during foaming of the emulsified suspensions and the final stability is achieved by a thermal treatment above the melting temperature of Al. The thin oxide layers surrounding the $\mathrm{Al}$ particles and the ascertained percolation of the molten metal are essential in this stage. The efficiency of the processing route is demonstrated with the essential requisites for successful foaming and the final structural stability. Furthermore, open cell Al-foams/zeolite composites exhibiting a hierarchical porous structure (nanoand macroscale) are produced by hydrothermal synthesis of Faujasite-like zeolite on the surface of the developed Al-foams. Due to the advantageous properties of zeolite X in $\mathrm{N}_{2}$ adsorption, the application of the composites for separation of $\mathrm{N}_{2}$ from air is specially envisaged.
\end{abstract}

Keywords Al foams - Highly porous materials . Zeolite

\section{Introduction}

Porous materials exhibit a combination of properties that cannot be obtained by their dense counterparts. These

S. Barg $(\bowtie) \cdot$ C. Soltmann · D. Koch · G. Grathwohl Keramische Werkstoffe und Bauteile, University of Bremen, Bremen, Germany

e-mail: sbarg@uni-bremen.de

A. Schwab - W. Schwieger

Lehrstuhl für Chemische Reaktionstechnik, University of Erlangen, Erlangen, Germany advantages include the high specific surface area, low weight and high permeability for fluids in the case of open celled structures. Metallic porous materials, in particular aluminum foams offer a unique combination of properties like thermal and electrical conductivity, plasticity, high impact resistance and sound absorption [1, 2]. Consequently, these metallic foams provoke important research and development activities and are recently used in numerous technological applications such as biomedical implants, filters, electrodes, catalysts and heat exchangers. Their characteristics make them also interesting in light weight constructions for energy absorption devices as well as for acoustic control, which are important fields for the automobile industry [2,3]. Furthermore, open cell foams are required for functional applications where transport, exchange or absorption processes of fluid phases through the microstructure take place.

Metallic foams can be processed by metal precursors in vapour, liquid, powdered or ion state $[1,2]$. Among the available processes, open cell foams have been produced from liquid metal by investment casting with polymeric foams [1] as well as by space-holder methods [4]. However, limitations of these techniques are found especially in the nature of the required space holders with melting temperatures higher than the metal itself, limiting therefore the choice of materials composition. Powdered metal can also be used for producing cellular metallic microstructures. Advanced techniques include the use of spaceholders for the determination of the pore morphology [5-7], the replication of polymeric sponge structure using coatings of metal powder slurries[1], as well as the foaming of metal powder slurries $[8,9]$.

Despite the progress in the processing of Al-foams, the use of space-holders is a limiting factor in the determination of the porosity parameters and leads to higher 
production costs while foaming of powder slurries results often in insufficient strength. Consequently, versatile, simple and low cost processing routes that allow easy control of the porosity parameters, resulting in mechanically stable open cell foams are still required.

Recently, a simple and low cost processing route based on the direct foaming of emulsified inorganic powder suspensions has been developed [10-12]. In this innovative process an alkane phase is emulsified in a stabilized aqueous inorganic powder suspension giving rise to low alkane phase (LAPES) [10] or high alkane phase emulsified suspensions (HAPE) [11-13] depending on the dispersed phase content. If the parameters of the emulsified suspension and the environmental conditions are favorably adjusted the evaporation of the alkane droplets during foaming leads to a time-dependent expansion of the emerging foam resulting in the controlled formation of highly porous microstructures with interconnected cells adjusted from low micro- up to millimeter scale. Given the versatility of the process, it can be easily adapted to different compositions resulting in mechanically stable metallic or ceramic parts including graded structures of the open porous interfaces [12].

Zeolites are crystalline aluminosilicates characterized by a well defined three-dimensional porous structure (pore size normally ranging between 0.2 and $2 \mathrm{~nm}$ ) with large specific surface area and ion-exchange properties resulting in a wide range of adsorption and selectivity properties. The use of zeolite coatings on different supports (metal substrates, porous $\mathrm{SiO}_{2}$, biomorphic and honeycombs ceramics as well as microcellular ceramic foams) has been widely investigated for several applications including gas separation processes, adsorption and catalysis. [14-17] In particular, Faujasite zeolites, e.g. zeolite X-type, are promising candidates for separation of gases due to their adsorption properties [15]. Furthermore, open cell foams are gaining increasing interest as support for zeolite crystallization due to their advantageous properties in comparison to the corresponding particle beds. Reactive supports containing one constituent of the builders of the zeolite ( $\mathrm{Al}$ or $\mathrm{Si}$ ) are expected to result in a good adherence between support and the zeolite layer. Microcellular polymer-derived SiOC ceramic foams as well as commercially available open cell Al-foams produced via investment casting (Duocell) have been used as support for in situ supported hydrothermal syntheses of MFI-type zeolite [16, 17].

Mechanically stable $\mathrm{Al}$ open cell foams are developed in this work by a novel direct foaming process in which a low concentrated alkane phase is emulsified in a stabilized $\mathrm{Al}$ powder suspension given rise to a low alkane phase emulsified Al suspension (Al-LAPES). In this case, the Al-LAPES foaming, which is provided by the evaporation of the alkane droplets, is accompanied by a time-dependent expansion of the emerging foam in a mold, with the shaping of the cellular part being accomplished in situ during the process. The foam rising from stable emulsified suspensions has to be consolidated before destabilization processes can lead to foam degradation. Because this consolidation process is mainly provided by drying the kinetics of foaming, bubble expansion, foam aging, and drying have to be considered as concurrent processes with their individual dependencies on the parameters of the system and the process. Recently the LAPES-based direct foaming process has been shown in more details for the alumina system [10]. In the case of Al-foams, a thermal treatment above the melting temperature of $\mathrm{Al}$ is essential. The controlled molten metal flow and the oxide layer surrounding the $\mathrm{Al}$ particles ensure the integrity of the structure.

The high specific surface area, selectivity and adsorption properties provided by zeolites, associated with the advantages of a metallic cellular structure may result in a composite with unique properties, improving the functionality and consequently propagating the application fields of these materials. The present work describes the in situ formation of Faujasite-like zeolites, e.g. a so called zeolite $\mathrm{X}$, on the surface of the developed novel open cell $\mathrm{Al}$ containing foams. In present paper the newly developed foams fulfil two functions: acting as support and direct $\mathrm{Al}$ source for zeolite crystallization.

\section{Materials and methods}

\subsection{Open cell Al-foams preparation process}

Open cell Al-foams are produced by a novel processing route based on the direct foaming of low alkane phase emulsified $\mathrm{Al}$ powder suspensions (Al-LAPES). The green foams with controlled porosity parameters are heated in controlled atmosphere above the melting temperature of Al. The controlled molten Al flow and the oxide layer surrounding the $\mathrm{Al}$ particles ensure the integrity of the porous microstructure.

The first step is then the preparation of a stabilized $\mathrm{Al}$ powder suspension. For this purpose dry Al powder (MEP 027, Ecka granulates) with an average particle diameter $\left(d_{50}\right)$ of $1.32 \mu \mathrm{m}$ and a specific surface area of $5.1 \mathrm{~m}^{2} / \mathrm{g}$ is slowly added to deionised water containing Dolapix CE-64 (Zschimmer \& Schwarz) (0.74 wt\% related to $\mathrm{Al}$ ) as negatively charged electrosteric dispersion agent for the realization of suspensions with $52 \mathrm{vol} \%$ particle content. Dispersion and homogenization is carried out in a laboratory mixer (Dispermat LC, VMA Getzmann $\mathrm{GmbH}$ ) at a stirring velocity of $2,500 \mathrm{rpm}$ for $20 \mathrm{~min}$. Afterwards the 
suspensions are subjected to de-aeration to remove undesired entrapped bubbles under reduced pressure $(5 \mathrm{kPa})$.

Al-LAPES are then prepared by adding 2.75 and 5.5 vol\% heptane $\left(\mathrm{C}_{7} \mathrm{H}_{16}\right)$ from Fluka and sodium lauryl sulphate (SLS) (BASF, Lutensid AS 2230) as anionic surfactant $(0.83 \mathrm{vol} \%)$. The surfactant adsorption reduces the heptane-Al suspension interfacial tension making it easier to create and maintain the large interfacial area associated with having many droplets as well as increasing the interfacial viscosity, what promotes stability during foaming as well. Emulsification is then supported by mechanical stirring for $2.5 \mathrm{~min}$ at $2,500 \mathrm{rpm}$ under reduced pressure at room temperature to avoid the abundant incorporation of air bubbles. A moderately reduced pressure of $10 \mathrm{kPa}$ was chosen with respect to the evaporation of heptane, which has a vapor pressure of $4.6 \mathrm{kPa}$ at $20{ }^{\circ} \mathrm{C}$.

The Al-LAPES are then poured into polymeric molds keeping the upper surface opened to the atmosphere. The following autonomous foaming process was realized in a clima chamber (Terra Universal) under controlled temperature and humidity $\left(35^{\circ} \mathrm{C}\right.$ and $\left.45 \%\right)$. After the consolidation, the aluminum foams were thermally treated in air under reduced pressure of 20 mbar, between 700 and $960{ }^{\circ} \mathrm{C}$ for $2 \mathrm{~h}$, with heating and cooling rates of 1 and $4 \mathrm{~K} / \mathrm{min}$, respectively.

\subsection{Zeolite crystallization}

Two routes of zeolite crystallizations were carried out following the approaches of 1.synthesis of a reference sample and 2. synthesis on the Al-foam surface.

Figure 1 shows the process sequences of the zeolite crystallization for the reference sample and for the
Al-foam. The main variation concerns the different composition of the sources for the crystallization and the application of the educts on the Al-foam after their mixture.

For the reference sample a recipe from literature was chosen to be able to compare the material synthesized on the foam with a reference material. The reference sample is prepared with the following reaction mixture on $\mathrm{Al}_{2} \mathrm{O}_{3}$ normalized molar ratio (according to Candamano et al. [15]):

$3.44 \mathrm{Na}_{2} \mathrm{O} * 1.65 \mathrm{~K}_{2} \mathrm{O} * 1 \mathrm{Al}_{2} \mathrm{O}_{3} * 0.8 \mathrm{Sio}_{2} * 122 \mathrm{H}_{2} \mathrm{O}_{2}$

For the reaction, $0.93 \mathrm{~g}$ sodium silicate $(25.5-28.5 \mathrm{wt} \%$ $\mathrm{SiO}_{2}, \quad 7.5-8.5$ wt $\% \quad \mathrm{Na}_{2} \mathrm{O}, \quad$ Merck), $0.68 \mathrm{~g}$ sodium hydroxide pellets (Merck), $1.12 \mathrm{~g}$ potassium hydroxide pellets (Merck), 1.00 g sodium aluminate ( $\mathrm{Al}$ as $\mathrm{Al}_{2} \mathrm{O}_{3} 50$ $56 \%$, $\mathrm{Na}$ as $\mathrm{Na}_{2} \mathrm{O} 40-45 \%$, Riedel-de Haen) and $10.28 \mathrm{~g}$ deionized water are needed. 1/5 of the water was mixed with the sodium aluminate and stirred until a homogenous solution was obtained, then $1 / 5$ of the water was mixed with the $\mathrm{NaOH}$-pellets, $1 / 5$ of the water was mixed with the $\mathrm{KOH}$-pellets and both are stirred until the pellets are dissolved. After that, sodium aluminate solution and the hydroxide solutions were mixed thoroughly. The sodium silicate and the rest of the water were given in the solution and stirred until a homogenous gel was formed. Then, the mixture was incubated for several times at $70{ }^{\circ} \mathrm{C}$, placed in a sealable, Teflon-lined autoclave and heated at $80^{\circ} \mathrm{C}$ in a convection oven for several reaction times. After hydrothermal treatment the samples were filtered and washed with deionized water/0.01 N sodium hydroxide solution and dried at $105^{\circ} \mathrm{C}$ for $12 \mathrm{~h}$.

For the hydrothermal treatment of the foams a reaction mixture with the following molar ratio was prepared:
Fig. 1 Comparison of process steps for reference zeolite sample and synthesis on Al-foam

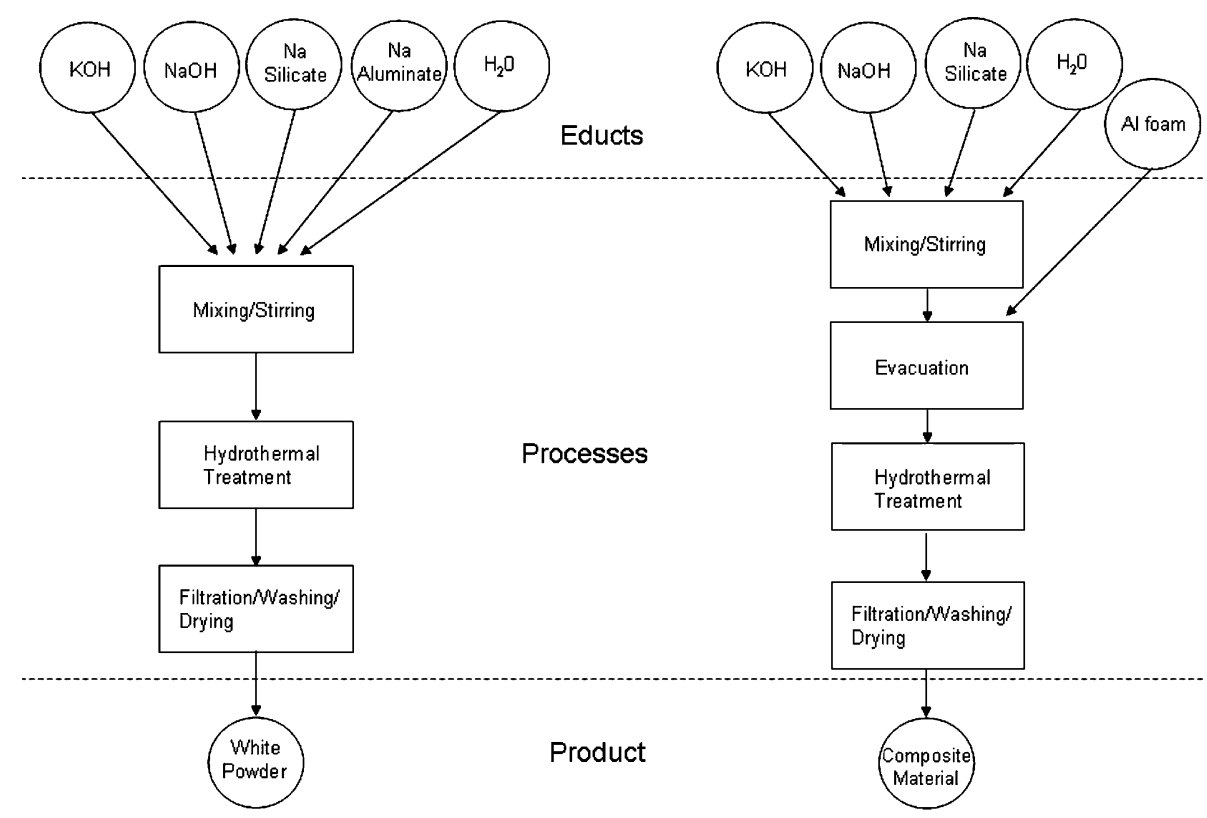




$$
70 \mathrm{Na}_{2} \mathrm{O} * 20 \mathrm{~K}_{2} \mathrm{O} * 10 \mathrm{SiO}_{2} * 1500 \mathrm{H}_{2} \mathrm{O}
$$

This molar composition is the modified recipe from above. The recipe shows the same molar ratios for sodiumand potassium source, but no external Al-source is used. The synthesis mixture was prepared by adding $1.51 \mathrm{~g}$ sodium silicate in a mixture of $2.9 \mathrm{~g}$ of $98.5 \mathrm{wt} \%$ sodium hydroxide solution and $1.52 \mathrm{~g}$ of a $85 \mathrm{wt} \%$ potassium hydroxide solution in $17.3 \mathrm{~g}$ water under vigorous stirring. The foams are placed into the synthesis mixture, and evacuated for $1 \mathrm{~h}$ to fill the cells with the reaction mixture avoiding air bubbles in the foam cell and ensuring a uniform distribution of the synthesis mixture. The synthesis was provided in sealable autoclaves at $80{ }^{\circ} \mathrm{C}$ for several reaction times. After synthesis, the Al-foam/ zeolite composite materials are treated in the same way as described for the reference samples.

\subsection{Characterization methods}

The morphology and microstructure of the sintered open cell $\mathrm{Al}$-foams as well as the $\mathrm{Al}$-foam/zeolite composites were analyzed from micrographs taken by Scanning Electron Microscopy, SEM (Camscan 24). Cell sizes were individually measured in planar sections with the help of Axio Vision LE image analysis program. The average cell sizes $\mathrm{d}_{50}, \mathrm{~d}_{10}$ and $\mathrm{d}_{90}$ were determined from the cumulative cell size distribution curves. The volumetric density $\rho_{\mathrm{v}}$ of the foams was determined from the mass and dimensions of the sintered bodies. The porosity $\mathrm{P}$ was then calculated as $\mathrm{P}=1-\rho_{\mathrm{v}} / \rho_{\mathrm{t}}$ with $\rho_{\mathrm{t}}\left(2.7 \mathrm{~g} / \mathrm{cm}^{3}\right)$ corresponding to the theoretical density of Al. The adsorption isotherms and the specific surface area of the Al-foam/zeolite composites were determined by $\mathrm{N}_{2}$ adsorption (ASAP 2010, Micromeretics). The materials were also analyzed via X-ray powder diffraction (X'pert Pro diffractometer, Philips Analytical) using $\mathrm{CuKa}$ radiation. The compressive strength of the cellular structures has been performed in a hydraulic mechanical testing machine (Zwick Model Germany), following the ASTM C133-94 standard using a cross-head speed of $1 \mathrm{~mm} / \mathrm{min}$ and a compressive load cell of 5,000 N. For each investigation 10 cylindrical samples measuring $10 \mathrm{~mm}$ of diameter and $10 \mathrm{~mm}$ of height have been tested.

\section{Results and discussion}

\subsection{Foaming of emulsified Al-powder suspensions} (Al-LAPES)

In this process, foaming proceeds while the conditions for stabilization are fulfilled for both parts of the system, namely the powder suspension and the alkane emulsion. The effects of the suspension stabilization and the foaming agent are taken into account in a way to control their interaction and consequently to prevent the destabilization and coagulation of the system. In previous work it has been shown that anionically stabilized emulsion represents the optimal condition for the effective foaming process of alumina suspensions [10]. Al particles are coated by a thin oxide layer upon the powder particle surface resulting in the same surface charge as $\mathrm{Al}_{2} \mathrm{O}_{3}$ particles. Consequently, in the present work the production of negatively charged Al-LAPES by the use of negatively charged surfactant and aluminum suspension resulted in homogenization and stabilization without coagulation in the systems.

The transition of the Al-LAPES (produced as described in chapter 2.1) to the wet foam starts as soon as the emulsification process is completed. Foaming proceeds as a consequence of the evaporation of the alkane phase resulting in the growth of the stabilized alkane bubbles and in a volume increase (Fig. 2a). At the same time when the bubbles are expanding, other physical processes like coalescence, Ostwald Ripening and drainage assist this process, decreasing the free energy of the system.
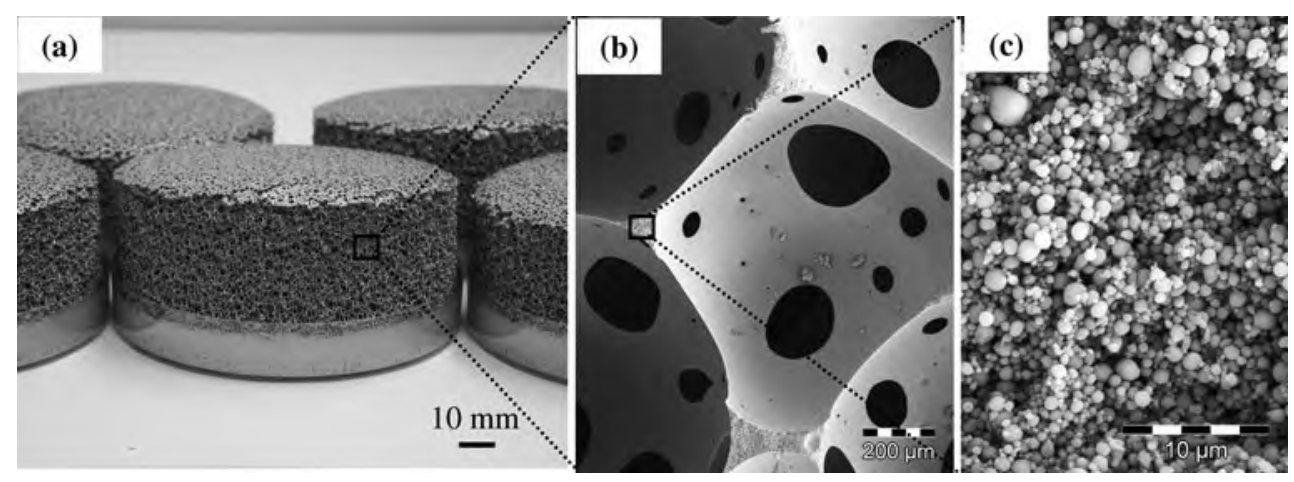

Fig. 2 Green Al-foams resulting from autonomous foaming process (a). Typical green foam cell morphology with open cell windows (b) and strut constituted of the $\mathrm{Al}$ powder particles packing (c) 
The setting of the foam is assisted by advancing drainage processes at plateau borders and thin films (as in the case of foaming of surfactant solutions), evaporation of the liquid phase (drying), and consequent rupture of the membranes (lamellae) between bubbles. The open up of the lamellae provides the windows between adjacent cells (Fig. 2b) which are connected with each other by finely grained struts (Fig. 2c). In this process, the particles network between bubbles represents an additional force against film thinning, ensuring high green stabilities.

Consequently, the concurrence between the bubble expansion kinetics and the setting of the foamed structure controls the foam cell size. Moreover, parameters like surfactant nature and content, vapor pressure and content of the vaporizing components, temperature, and humidity during foaming also influence these mechanisms and determinate the foam structure in green (Fig. 2) as well as in consolidated state. The mechanisms taking place during the foaming process have been further described for alumina foams [10].

\subsection{Consolidation of the $\mathrm{Al}$ open cell foams}

Green foams with adjusted porosity parameters produced from Al-LAPES containing varying heptane content ( 2.75 and $5.5 \mathrm{vol} \%$ ) are further consolidated by a controlled thermal treatment in air under reduced pressure (20 mbar) above the $\mathrm{Al}$ melting point. The final microstructures of $\mathrm{Al}$ open cell foams are shown in Fig. 3. These materials are characterized by high porosities (95-97\%) with highly interconnected cells uniformly distributed throughout the sample. Higher concentration of heptane (Fig. 3 b) turns out as higher foam growth resulting in thinner cell walls as a consequence of the higher surface area generated by the droplets. The materials present cell sizes of 1.4 and $1.5 \mathrm{~mm}$ $\left(\mathrm{d}_{50}\right)$ and strut thicknesses of 0.3 and $0.2 \mathrm{~mm}\left(\mathrm{~d}_{50}\right)$ for heptane concentrations of 2.75 and $5.5 \mathrm{vol} \%$, respectively. The successful realization of these highly porous structurally stable Al-foams has been achieved under the favorable foaming conditions due to the state of interaction between the negatively charged suspension and the emulsion. The structural stability during foaming has been provided by the cell walls of the emerging foam, appearing as undamaged thin barriers between the growing gas bubbles. It is obvious that these membranes fulfill their tasks in a most impressive way when the powder suspension is foamed to such high porosity levels (Fig. 2).

The oxide shells surrounding the particles result in a stable oxide network which keeps the foam cellular macrostructure unchanged even after the molten metal flows from the particles. There is, however, a significant change of the microstructure inside the foam struts when the powder particles lose their identity and merge to a
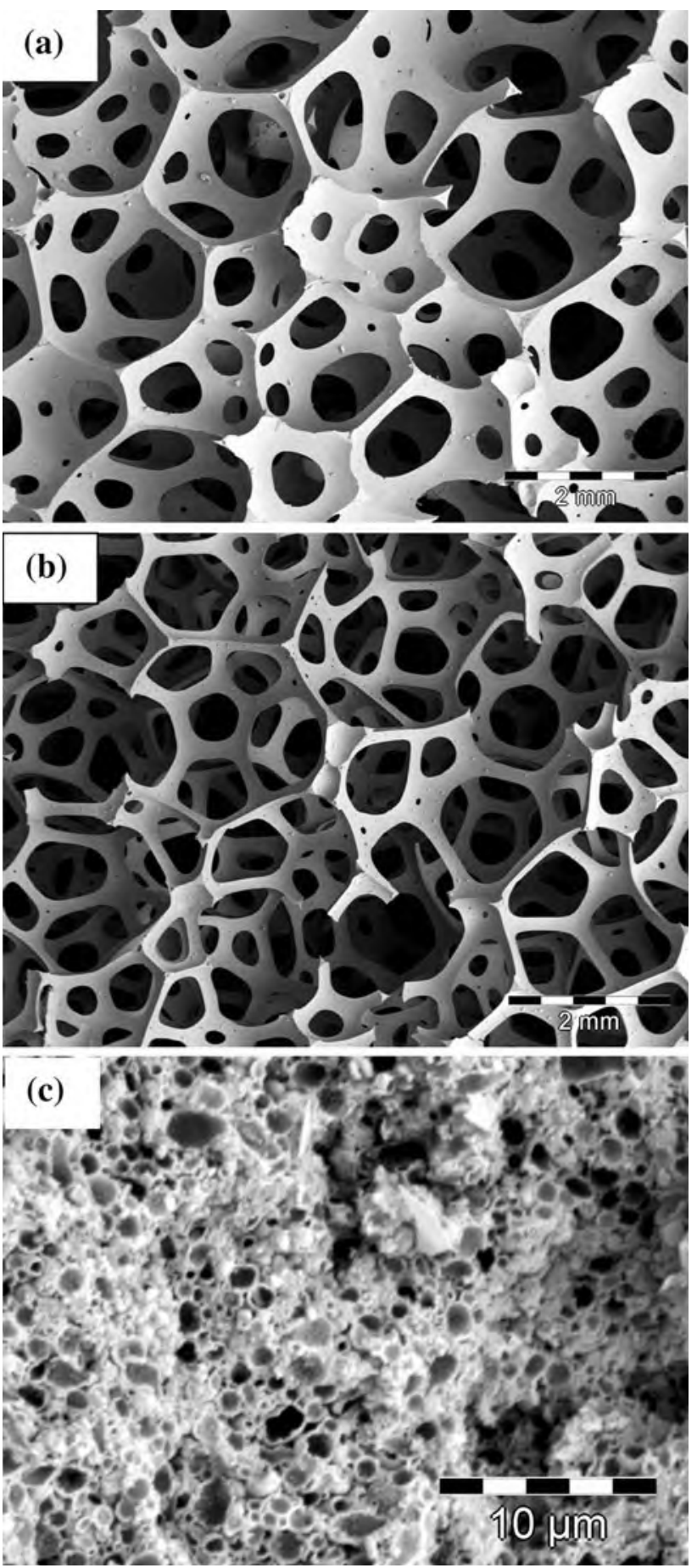

Fig. 3 Microstructure of open cell Al-foams produced from Al-LAPES containing 2.75 (a), and 5.5 vol\% heptane (b) and (c). The emulsified suspensions were foamed under controlled temperature $\left(35^{\circ} \mathrm{C}\right)$ and humidity $(45 \%)$. Subsequent thermal treatment was realized at $820^{\circ} \mathrm{C}$ for $2 \mathrm{~h}$ in air under reduced pressure of $20 \mathrm{mbar}$. In c an Al-foam strut is shown with hollow oxide shell residues

continuous Al matrix phase by the melting process. A considerable gain in strength is also reached. The presence of oxide layers surrounding the $\mathrm{Al}$ particles is essential for the structural integrity of the foams during this stage. At a 
critical temperature (depending on the relation between the oxide layer thickness and the particle size) the oxide layer is partially disrupted allowing a controlled percolation of the molten metal from the particles interior. Efficient control of this molten metal flow is crucial for the stability of the foams. The oxide layer thickness to particle volume relation and the molten $\mathrm{Al}$ flow can be adjusted mainly by the powder particle size and size distribution, the maximum temperature and dwelling time as well as the surrounding atmosphere for this thermal treatment step.

The mechanical stability of the foams is a further target of the thermal treatment at $800{ }^{\circ} \mathrm{C}$ for $2 \mathrm{~h}$ resulting in compressive strengths of $1.3 \pm 0.3 \mathrm{MPa}$. The further increase of the thermal treatment temperature $\left(860{ }^{\circ} \mathrm{C}\right)$ increased the mechanical strength to 2,6 $\pm 0.5 \mathrm{MPa}$. Lower temperatures (starting from $700{ }^{\circ} \mathrm{C}$ ) resulted in a low connectivity between the particles as no sufficient percolation of the molten $\mathrm{Al}$ matrix has taken place. Beyond the critical temperature the oxide layer of the particles are partially disrupted and the molten metal flow through the microstructure is adequate to provide good connections between the particles (Fig. 3c). Compared with conventional $\mathrm{Al}$ foams the developed materials are more brittle due to the presence of the oxide layers. The stress strain curve presents a plateau region typical of brittle crushing. However, a narrow Al particle size distribution and uniform oxide layer thickness ensure that the oxide shells of most particles are disrupted at the same time when the critical temperature is reached. Flow and wetting processes of molten $\mathrm{Al}$ are then effective to provide a network like microstructure of a continuous Al-matrix with interconnected oxide particles as residues of the particle shells. The thermal treatment should be interrupted after the simultaneous particle shell disruption has taken place in order to preserve this composite microstructure with a moderate capability of elastic-plastic deformation.

The effects of thermal treatments under extreme conditions are demonstrated in Fig. 4. After annealing up to $900{ }^{\circ} \mathrm{C}$ the struts are constituted by the percolating $\mathrm{Al}$ phase including residues of the oxide shells (Fig. 4b). Occasionally, Al spheres in different sizes, namely, around $20 \mu \mathrm{m}$ (Fig. 4b) as well as $400 \mu \mathrm{m}$ (Fig. 4a, d) are found attached to the surface of the cells. This can be understood as rudimentary formation of molten beads which are not incorporated in the $\mathrm{Al}$ matrix as it is prevented by their oxide shell. With the further increase of the annealing temperature up to $960{ }^{\circ} \mathrm{C}$ a higher amount of molten $\mathrm{Al}$ can escape from the strut cores and cumulate in a single spherical agglomerate (Fig. 4c). Discharging the liquid Al phase from the struts leaves behind the fine network of struts consisting of the oxide grains as residues from the surface scale of the oxidized Al foam (Fig. 4d).
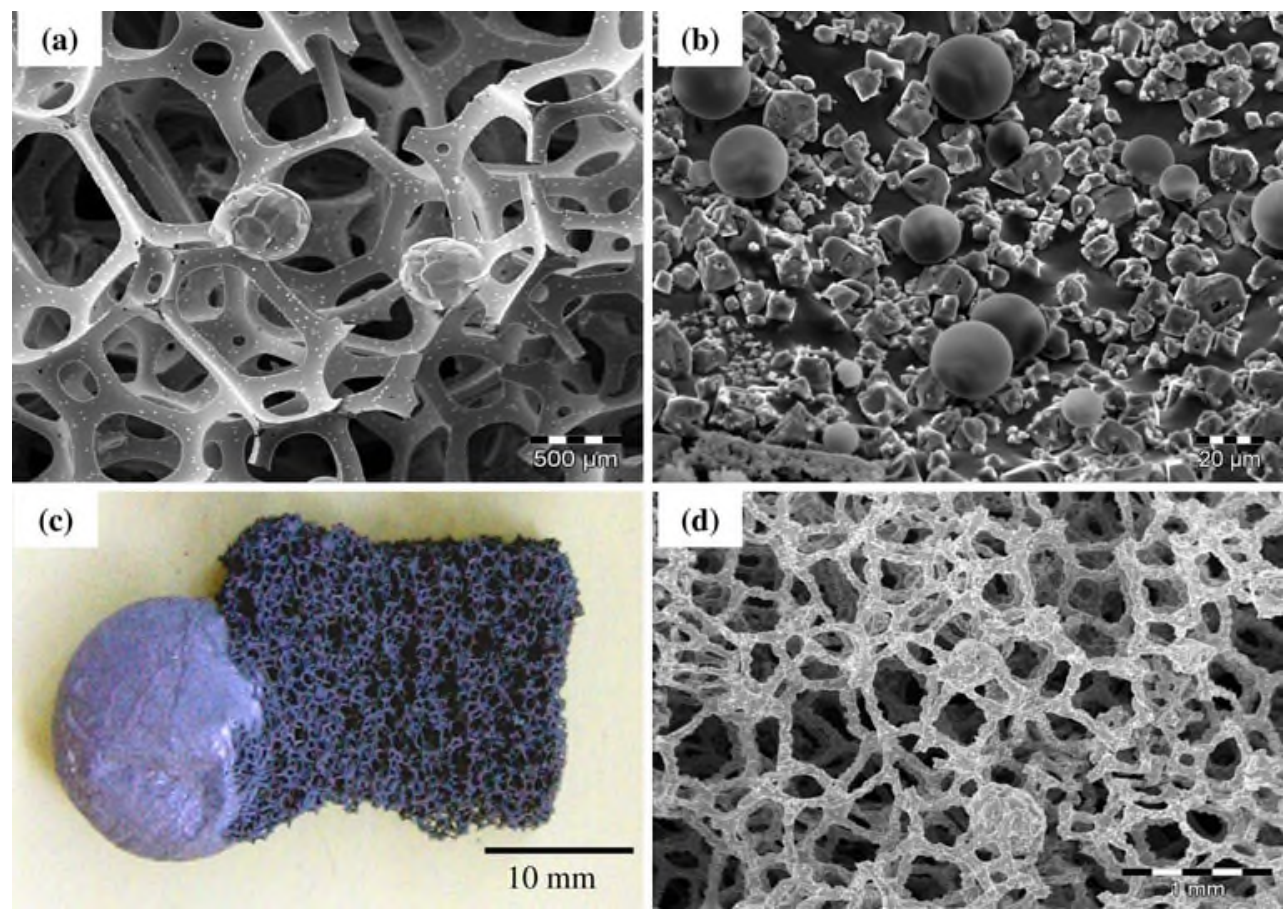

Fig. 4 Open cell Al-foams over aged at $900{ }^{\circ} \mathrm{C}\left(\right.$ a), (b) and $960{ }^{\circ} \mathrm{C}$ (c), (d) under reduced air pressure of 20 mbar. Molten Al beads are formed at these high temperatures leading to the collection of the total liquid volume in a half-spherical body at $960{ }^{\circ} \mathrm{C}(\mathbf{c})$. The residual

foam consists then of the oxide scale network (d) which is in contrast to the Al-network at lower temperatures (a) also being stabilized by thin oxide scales 
In the direct foaming process of molten metal the effect of oxide scaling, normally present in the precursor material, is known to be essential for the foaming behavior and stability. Oxide particles withstand forces from one interface to the other in the cell walls, balancing then capillary effects and providing stability [18-21].

It is assumed, that foaming of molten metal follows similar principles as foaming of metal powder suspensions. However, while in foaming of metal melts oxide particles bring stability at the same time when the foam structure is formed, the foamed structure of inorganic powder suspensions is controlled in the green state where the particles and their interaction with the system play important roles for the stability of the foams [10]. Moreover, during heat treatment the oxide particles network is essential for keeping the structural integrity.

The presented processing route is a versatile tool for the development of Al-foams with highly interconnected cells and controlled porosity parameter which can be designed following the requirements of selected applications.

\subsection{Open cell Al-foam/zeolite composites}

The stabilized open cell Al-foams were prepared with the purpose to serve as reactive support for zeolite crystallization. The hydrothermal treatment with the in chapter 2.2 described reaction mixture was undertaken with the thicker cell wall supports (Fig. 3a). These structures provide a higher stability and a larger amount of Al for the zeolite synthesis. Moreover, in the reactive process while hydrothermal reactions between alkaline synthesis mixture and support take place, elemental $\mathrm{Al}$ gets dissoluted from the foam. This process could lead to support disintegration. Consequently, a compromise between maximum reactivity synthesis of zeolite associated with mechanical stability (enduring $\mathrm{Al}$ support) has to be established.

The optimized synthesis condition $\left(80^{\circ} \mathrm{C} / 80 \mathrm{~h}\right)$ leads to a stable composite material. In Fig. 5 diffraction patterns of a zeolite X standard (from CWK, Bad Köstritz), the hydrothermally treated foam, an untreated foam and the reference sample zeolite $\mathrm{X}$ after Candamano are shown. The XRD pattern of the treated foam confirms the presence of a zeolite $\mathrm{X}$ on the support. Furthermore the pattern of the treated foam/composite material shows smaller intensities of the support reflections compared to the untreated foam.

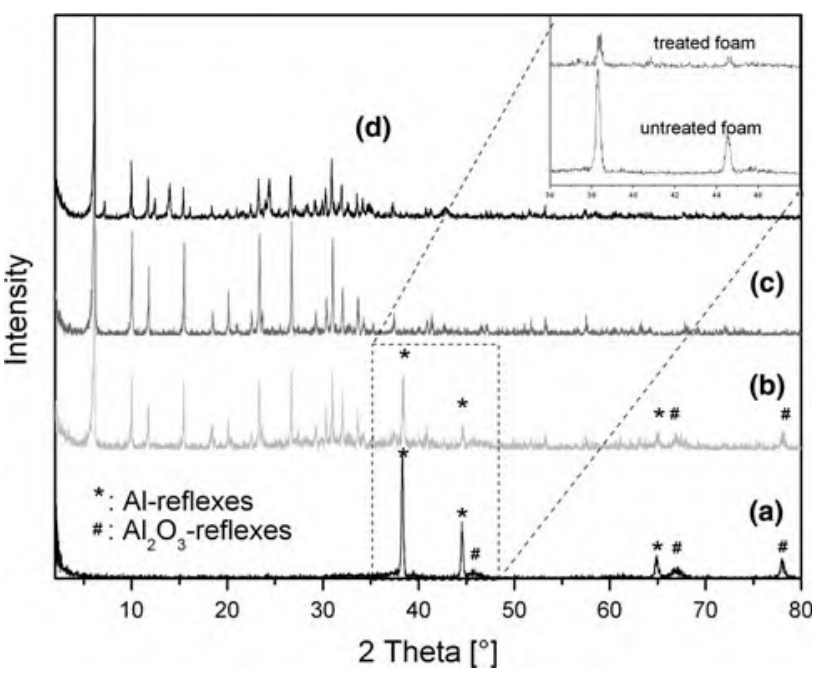

Fig. 5 XRD patterns of samples and standards with marked Al- and $\mathrm{Al}_{2} \mathrm{O}_{3}$-reflexes. a untreated foam, intensity reduced by factor 0.5 ; $\mathbf{b}$ treated foam, intensity reduced by factor $2 / 3$; c zeolite X Standard CWK, Bad Köstritz, 1xintensity d reference sample, zeolite $X$ after Candamano, 1xintensity. All unmarked reflexes of Al-foam/zeolite composite $(b)$ are related to zeolite $\mathrm{X}$

In addition, the intensities of the Al-reflections $[2 \Theta$ at 38.3 , 44.6 and 64.8] are decreasing after treatment to a higher degree compared to the $\mathrm{Al}_{2} \mathrm{O}_{3}$-reflections of the support. This corroborates the preferred dissolution of the Al-fraction of the support during hydrothermal treatment. Table 1 summarizes the intensity ratios. The untreated and hydrothermally treated foams show intensity ratios of 3 and 1.6, respectively. This indicates the partial consumption of $\mathrm{Al}$ during the treatment of the foam, which is necessary for the zeolite $\mathrm{X}$ formation.

Figure 6 shows fracture surfaces of untreated (upper row) and treated foams (lower row). The treated support manifests layers of crystallized zeolite (20 to $40 \mu \mathrm{m}$ thick) on the support, defect-free surfaces and interfaces between zeolite and the $\mathrm{Al}$ support.

In Fig. 7 the reference diffraction patterns from type $X$ and Y (PDF 01-072-2421 for X-type and PDF 01-076-0108 for Y-type) are shown in comparison to our obtained composite material and the synthesized zeolite $\mathrm{X}$ according to Candamano [15]. There is a shift in the 2 Theta positions to higher 2 Theta positions for zeolite Y compared to both: the zeolite $X$ and the treated foams. Table 2 summarizes the $2 \Theta$ values for some selected hkl-planes for the $\mathrm{X}$ - and Y-type

Table 1 XRD relative reflex intensities for treated and untreated foams

\begin{tabular}{lllr}
\hline Al foam & Relative reflex intensity & Area of \\
\cline { 3 - 5 } & & $\mathrm{Al}_{\text {-reflexes }}$ & $\mathrm{Al}_{2} \mathrm{O}_{3}$-reflexes \\
\hline Untreated & $3.0\left(2 \Theta_{\mathrm{Al}}\right.$ at $38.3,44.6$ and $64.8 ; 2 \Theta_{\mathrm{Al} 2 \mathrm{O} 3}$ at $45.6,67$ and 78$)$ & 55.23 & 18.26 \\
Treated & $1.6\left(2 \Theta_{\mathrm{Al}}\right.$ at $38.3,44.6$ and $65 ; 2 \Theta_{\mathrm{Al} 2 \mathrm{O} 3}$ at 67 and 78$)$ & 13.93 & 8.96 \\
\hline
\end{tabular}



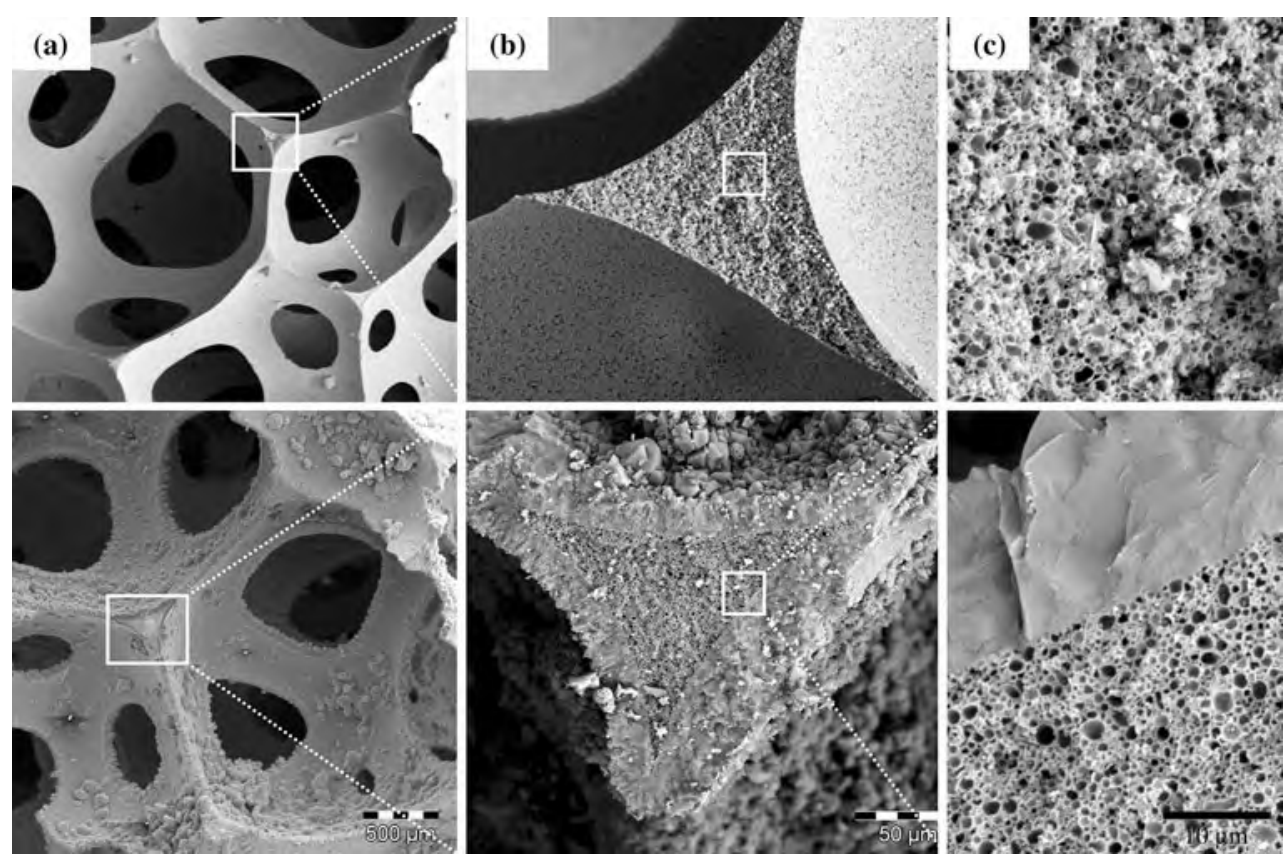

Fig. 6 Fracture surfaces of untreated open cell $\mathrm{Al}$ foam (upper row) and of open cell $\mathrm{Al}$ foam/zeolite composite (lower row). Untreated and treated cell walls (a) and struts (b). In $\mathbf{c}$ the microstructure of

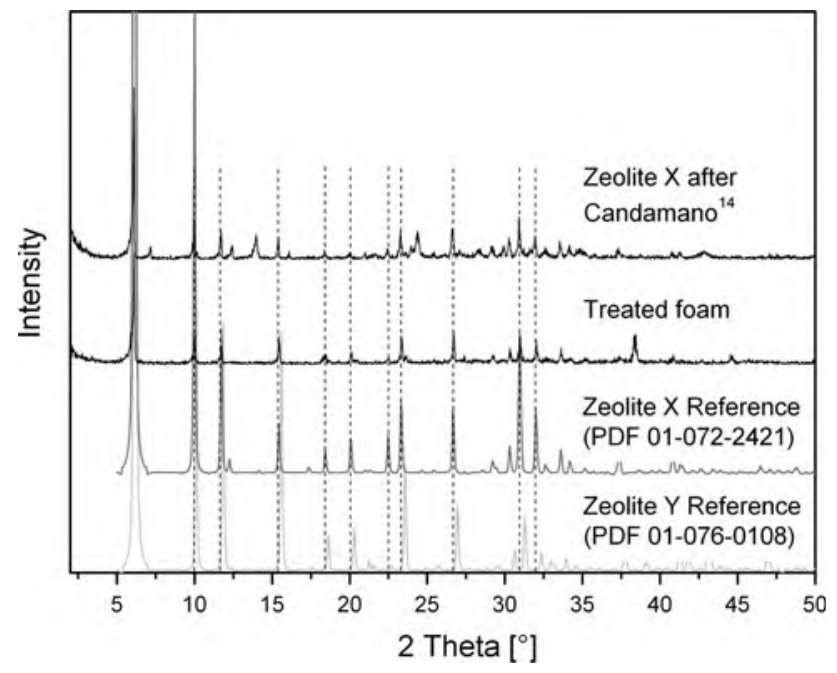

Fig. 7 Zeolite type $\mathrm{X}$ and $\mathrm{Y}$ reference diffraction patterns (ICDD; PDF-database) compared with the synthesised composite material and zeolite $\mathrm{X}$ reference sample

zeolite and the resulting differences $\Delta 2 \Theta$ to the treated foam/composite material. The resulting distance of the selected 220-/555-planes are given in Table 3 showing the expansion of the framework of zeolite $\mathrm{Y}$ due to the higher $\mathrm{Al} / \mathrm{Si}$-ratio. Both results indicate that the zeolite fraction of the treated foam is matching better to the zeolite X-type. Therefore one can conclude that the described synthesis leads to a X-type zeolite on the used Aluminium foams.

The $\mathrm{N}_{2}$ adsorption isotherm curves are presented in Fig. 8. High adsorption capacity is revealed in case of pure untreated strut and the defect-free perfect connection between foam strut and the crystallized zeolite layer is shown

zeolite powder while the untreated foam shows a negligible adsorption capacity. The synthesised composite, however, shows a strong increase in $\mathrm{N}_{2}$ adsorption at very low relative pressures (isotherm type 1). The negligible adsorption capacity of the Al support combined with the high adsorption capacity of pure zeolite explains the $\mathrm{Al}$ foams/zeolite composites adsorption capacity. Furthermore, the slight hysteresis in desorption curve might correspond to capillary condensation what could indicate a low amount of mesoporosity (isotherm type 4) also presented in the zeolite sample. The composite presents a surface area of $267 \mathrm{~m}^{2} / \mathrm{g}$ which manifests the strong increase compared with the BET- surface of $4 \mathrm{~m}^{2} / \mathrm{g}$ in the untreated foam. The comparison of these $\mathrm{N}_{2}$ adsorption isotherm curves confirms the formation of microporous zeolite on the open cell Al-foams.

In summary it could be demonstrated that the zeolite synthesised on the Al-foam is rather matching with zeolite $\mathrm{X}$ than with zeolite $\mathrm{Y}$. A pure zeolite phase is produced on the surface of the metallic foam.

Figure 9 illustrates the potential of this technique to produce net-shaped inorganic foamed parts. Cartridges which have been implemented by the metallic foam and the zeolite coated foam are presented in this figure as they may be used in future for separation processes.

\section{Conclusions}

Open cell Al-foams were produced by a novel, versatile and simple processing route based on the direct foaming of 
Table 22 theta positions for hkl indices of standard zeolites $\mathrm{X}$ and $\mathrm{Y}$ compared with treated foam

\begin{tabular}{|c|c|c|c|c|c|}
\hline FAU-indices & $\begin{array}{l}\text { Zeolite X } \\
\text { (PDF 01-072-2421) }\end{array}$ & $\begin{array}{l}\text { Treated } \\
\text { foam }\end{array}$ & $\begin{array}{l}\text { Zeolite Y } \\
\text { (PDF 01-076-0108) }\end{array}$ & $\begin{array}{l}\Delta 2 \Theta \text { zeolite } \\
\mathrm{X} / \text { treated foam }\end{array}$ & $\begin{array}{l}\Delta 2 \Theta \text { zeolite } \\
\text { Y/treated foam }\end{array}$ \\
\hline$h k l$ & 2 theta position $\left[{ }^{\circ}\right]$ & & & & \\
\hline 220 & 10.00 & 10.01 & 10.31 & 0.01 & 0.30 \\
\hline 311 & 11.73 & 11.75 & 12.10 & 0.02 & 0.35 \\
\hline 331 & 15.43 & 15.45 & 15.92 & 0.02 & 0.47 \\
\hline 511 & 18.42 & 18.47 & 19.01 & 0.05 & 0.54 \\
\hline 440 & 20.07 & 20.11 & 20.71 & 0.05 & 0.6 \\
\hline 620 & 22.47 & 22.51 & 23.19 & 0.04 & 0.68 \\
\hline 533 & 23.31 & 23.34 & 24.06 & 0.03 & 0.72 \\
\hline 642 & 26.65 & 26.68 & 27.52 & 0.03 & 0.84 \\
\hline 555 & 30.94 & 30.97 & 31.95 & 0.03 & 0.98 \\
\hline 840 & 31.98 & 32.02 & 33.03 & 0.04 & 1.01 \\
\hline
\end{tabular}

Table $3 d$-values of zeolite $\mathrm{X}$, zeolite $\mathrm{Y}$ and treated foam

\begin{tabular}{llll}
\hline hkl & \multicolumn{2}{l}{-value $(\mathrm{nm})$} & \\
\cline { 2 - 4 } & X type & Treated foam & Y type \\
\hline 220 & 8.849 & 8.836 & 8.576 \\
555 & 2.890 & 2.888 & 2.801 \\
\hline
\end{tabular}

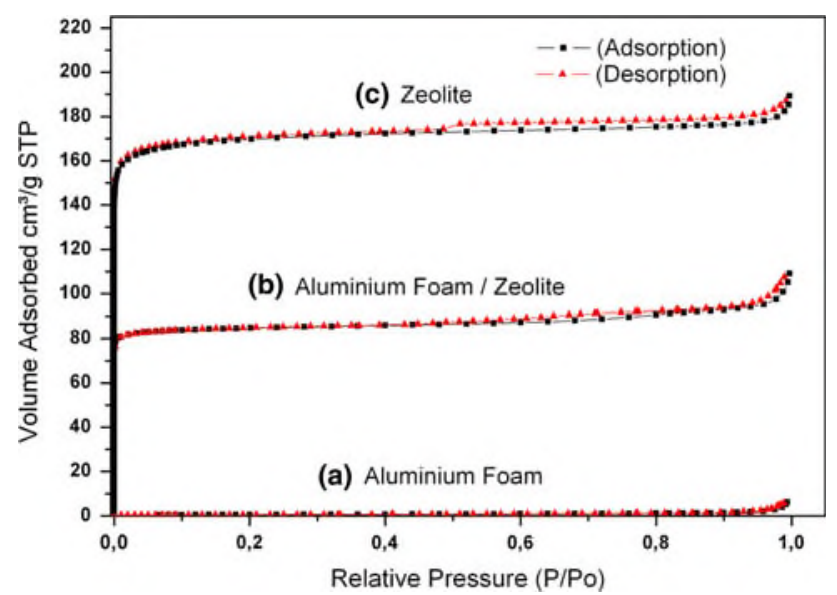

Fig. $8 \mathrm{~N}_{2}$ adsorption/desorption isotherms: $a$ untreated Aluminium foam; $b$ Aluminium Foam/zeolite composite; $c$ zeolite X-type powder

low alkane phase emulsified Al suspension (Al-LAPES). Negatively charged Al-LAPES favoured foaming leading to stable green foams with controlled porosity parameters. The effective control of the alkane content in Al-LAPES leads to interconnected cells with adjustable wall thickness. Furthermore, the remaining thin oxide layer surrounding the $\mathrm{Al}$ particles as well as the controlled percolation of molten $\mathrm{Al}$ during heat treatment ensured final structural integrity.

Stable foam/zeolite composites with defect free interfaces and high surface areas due to the microporous zeolite

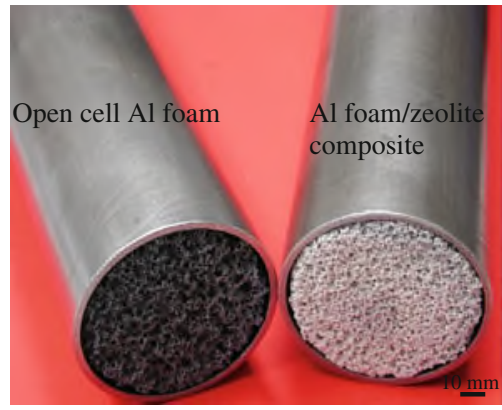

Fig. 9 Filter cartridge containing open cell $\mathrm{Al}$ foam as well as Alfoam/zeolite composite. The Al-foams are produced from Al-LAPES containing $2.75 \mathrm{vol} \%$ heptane and thermally treated at $820^{\circ} \mathrm{C}$ in air pressure of $20 \mathrm{mbar}$ (Fig. 3a). Zeolite crystallization at $80^{\circ} \mathrm{C}$ for $80 \mathrm{~h}$

were successfully developed. The presence of oxide layers surrounding the $\mathrm{Al}$ particles was also essential in this stage for the control of zeolite crystallization. Furthermore, the use of a reactive support, providing the $\mathrm{Al}$ source for zeolite crystallization provided a good adherence between the zeolite layer and the remaining support.

The high surface area, selectivity and adsorption properties provided by zeolites, associated with the advantages of the metallic cellular structure itself improve the functionality and consequently the application fields of these materials. Due to the advantageous properties of zeolite $\mathrm{X}$ for $\mathrm{N}_{2}$ adsorption, the application of the composites in separation of $\mathrm{N}_{2}$ from $\mathrm{O}_{2}$ is envisaged.

Acknowledgements The authors would like to thank the AiF for funding parts of this work within the project "Multifunktionelle Keramikschäume $14260 \mathrm{~N}$ ". The assistance of Hailing Wang concerning the practical work is also gratefully appreciated. The authors A. Schwab and W. Schwieger also gratefully acknowledge the funding of the German Research Council (DFG), which, within the framework of its 'Excellence Initiative' supports the Cluster of Excellence 'Engineering of Advanced Materials' (www.eam.uni-erlangen.de) at the University of Erlangen-Nuremberg. 


\section{References}

1. J. Banhart, Manufacture, characterisation and application of cellular metals and metal foams. Prog. Mater. Sci. 46(6), 559-U3 (2001)

2. L.-P. Lefebvre, J. Banhart, D.C. Dunand, Porous metals and metallic foams: current status and recent developments. Adv. Eng. Mater. 10(9), 775-787 (2008)

3. J. Banhart, Aluminium foams for lighter vehicles. Int. J. Vehicle. Des. 37(2/3), 114-125 (2005)

4. J.F. Despois, Y. Conde, C. San Marchi, A. Mortensen, Tensile behavior of replicated aluminium foams. Adv. Eng. Mater. 6(6), 444-447 (2004)

5. M. Bram, C. Stiller, H.P. Buchkremer, D. Stover, H. Baur, Highporosity titanium, stainless steel, and superalloy parts. Adv. Eng. Mater. 2(4), 196-199 (2000)

6. B. Jiang, N.Q. Zhao, C.S. Shi, X.W. Du, J.J. Li, H.C. Man, A novel method for making open cell aluminum foams by powder sintering process. Mater. Lett. 59(26), 3333-3336 (2005)

7. Y.Y. Zhao, D.X. Sun, A novel sintering-dissolution process for manufacturing Al foams. Scripta Mater. 44(1), 105-110 (2001)

8. S.B. Kulkarni, P. Ramakrishnan, Foamed aluminium. Int. J. Powder Metall. 9(1), 41-45 (1973)

9. J.P. Drolet, Low-density foams produced from aluminium powders. Int. J. Powder Metall. 13(3), 221-225 (1977)

10. S. Barg, C. Soltmann, M. Andrade, D. Koch, G. Grathwohl, Cellular ceramics by direct foaming of emulsified ceramic powder suspensions. J. Am. Ceram. Soc. 91(9), 2823-2829 (2008)

11. S. Barg, E.G. de Moraes, D. Koch, G. Grathwohl, New cellular ceramics from high alkane phase emulsified suspensions (HAPES). J. Eur. Ceram. Soc. 29(12), 2439-2446 (2009)
12. S. Barg, D. Koch, G. Grathwohl, Processing and properties of graded ceramic filters. J. Am. Ceram. Soc. 92(12), 2854-2860 (2009)

13. J. Hüppmeier, S. Barg, M. Baune, D. Koch, G. Grathwohl, J. Thöming, Oxygen feed membranes in autothermal steam-reformers-a robust temperature control. Fuel (in press, corrected proof)

14. C.R. Rambo, J. Junkes, H. Sieber, D. Hotza, Biomorphic ceramics as porous supports for zeolite coating. Adv. Sci. Technol. 45, 819-828 (2006)

15. S. Candamano, P. Frontera, F. Crea, R. Aiello, In situ synthesis of FAU-type zeolite layer on cordierite support. Top. Catal. 3031(1), 369-373 (2004)

16. P.C.A. Zampieri, G.T.P. Mabande, T. Selvam, W. Schwieger, F. Scheffler, Zeolite coatings on microcellular ceramic foams: a novel route to microreactor and microseparator devices. Adv. Mater. 16(9-10), 819-823 (2004)

17. F. Scheffler, R. Herrmann, W. Schwieger, M. Scheffler, Preparation and properties of an electrically heatable aluminium foam/ zeolite composite. Microporous Mesoporous Mater. 67, 53-59 (2004)

18. J. Banhart, Metal foams: production and stability. Adv. Eng. Mater. 8(9), 781-794 (2006)

19. C. Korner, M. Arnold, R.F. Singer, Metal foam stabilization by oxide network particles. Mater. Sci. Eng. A-Struct. Mater. Prop. Microstruct. Process 396(1-2), 28-40 (2005)

20. G. Kaptay, Interfacial criteria for stabilization of liquid foams by solid particles. Colloids Surf. A Physicochem. Eng. Asp. 230(13), 67-80 (2003)

21. A. Dudka, F. Garcia-Moreno, N. Wanderka, J. Banhart, Structure and distribution of oxides in aluminium foam. Acta Mater. 56(15), 3990-4001 (2008) 